\title{
Serviços ambientais gerados nas principais bacias hidrográficas do estado de Santa Catarina
}

\author{
Environmental Services Generated In The Major River Basins \\ Of The Santa Catarina state, Brazil
}

\section{Luiz Carlos Pittol Martini}

Submetido em: $14 / 07 / 16$ Revisado em: 2510/16 Aprovado em: 17/11/16
RESUMO: Os pagamentos por serviços ambientais ou ecossistêmicos constituem-se em instrumentos de apoio para execução de propostas voltadas à gestáo de recursos naturais e estão adquirindo importância no Estado de Santa Catarina desde a instituição do Programa Estadual de Pagamento por Serviços Ambientais, em 2010. Nesse sentido, o objetivo central deste trabalho foi estruturar um quadro sinótico dos serviços ambientais mais relevantes distribuídos nas principais bacias hidrográficas catarinenses, agrupandoos em três categorias abrangentes: (1) serviços de provisão, (2) serviços de regulação e (3) serviços culturais. Os serviços ambientais identificados nas principais bacias hidrográficas catarinenses receberam um nível de importância baseado em dados quantitativos obtidos em diversas referências. $\mathrm{O}$ resultado final obtido foi estruturado em quadros com a distribuição por bacia hidrográfica dos serviços ambientais mais significativos, os quais podem servir como orientação para aplicação do pagamento por serviços ambientais em áreas com usos da terra que conflitam com a proteção de ecossistemas.

Palavras-chave: Gestão ambiental; Instrumentos econômicos; Agricultura; Recursos hídricos.
ABSTRACT: The payment for environmental or ecosystem services are support tools for implementation of natural resource management proposals and they are gaining importance in the Santa Catarina State since the establishment of the State Program for Environmental Services Payment in 2010. In this regard, the main objective of this work was to structure a synoptic framework of the most important environmental services distributed in the major river basins of the Santa Catarina State, grouping them into three main categories: (1) provision services, (2) regulatory services and (3) cultural services. The environmental services identified in the major river basins of the Santa Catarina State received an importance level based on quantitative data obtained in several references. The end result was structured in charts with the distribution of the most significant environmental services by river basin, which can serve as guidance for application of the payment for environmental services in areas with conflicts between land uses and ecosystems protection.

Keywords: Environmental management; Economic instruments; Agriculture; Water resources.

\section{INTRODUÇÃO}

As expressôes "serviços ambientais", "serviços ecossistêmicos" e "serviços da natureza" normalmente são empregadas com significados equivalentes na bibliografia que aborda a temática ambiental e procuram traduzir os benefícios para as pessoas advindos do uso dos recursos naturais ou das funçóes ambientais. Como a palavra natureza está mais ligada a entes naturais (isto é, sem a intervenção humana) e o termo ecossistêmico pode-se referir a um ecossistema em particular, alguns autores têm dado preferência ao uso da denominação "serviços ambientais" (CONSTANZA et al., 1997; GUEDES E SEEHUSEN, 2011; SANTOS et al., 2012; PAGIOLA et al., 2013).

Em um esforço para delimitar o tema e para estabelecer distinçôes entre funçôes e serviços ambientais, Constanza et al. (1997) indicam que as funçôes estão associadas aos componentes de um ecossistema ou aos processos biológicos, geoquímicos e físicos que nele ocorrem. Nessa definição, as funções relacionam-se aos componentes estruturais - vegetação, água, solo, atmosfera e biota - e aos modos como esses componentes atuam de forma recíproca interna e externamente a outros ecossistemas. Por sua vez, os 
bens ambientais (tais como os alimentos) e serviços (tal como assimilação de efluentes) representam os benefícios para a população humana derivados direta ou indiretamente das funçôes ambientais. Para simplificação, os autores sugerem incluir os bens no termo "serviços". Generalizando, uma função é um atributo natural de um ecossistema e um serviço é quando uma ou mais funçôes desse ecossistema passam a adquirir um valor instrumental para os seres humanos.

A delimitação do significado e a necessidade de caracterização dos serviços ambientais surgiram em decorrência da difusão, principalmente a partir do começo deste de século, da alternativa econômica denominada "pagamento por serviços ambientais (PSA)", que tem sido cada vez mais indicada como um instrumento eficaz de apoio à gestão de recursos naturais (MILLENNIUM ECOSYSTEM ASSESSMENT, 2005). De acordo com Naeem et al. (2015), os mecanismos envolvidos no PSA estão associados diretamente a pagamentos por desempenho ambiental e são vistos como alternativas eficientes para complementar as abordagens mais tradicionais de gestâo, que se baseiam principalmente na regulaçáo do uso de bens e serviços ambientais ou em medidas restritivas de ocupação de espaços territoriais. De forma distinta do modelo baseado na aplicaçáo do princípio poluidor-pagador (PPP), o PSA requer que as entidades públicas ou privadas beneficiadas pela proteçáo ambiental encarreguem-se por pagamentos a serem transferidos às entidades promotoras das açóes de proteção ou melhoria ambiental. As entidades habilitadas a receberem os pagamentos podem ser públicas (geralmente governos) ou privadas, sendo estas representadas por um indivíduo em particular, por empresas ou mesmo por comunidades.

Tanto a abordagem PPP como a PSA geralmente implicam reconhecimento do direito de uso privado de certos recursos naturais considerados como bens públicos na legislação brasileira, caso dos recursos hídricos e alguns tipos de áreas de preservação permanente. Tal reconhecimento constitui-se em uma aplicação direta do que às vezes é chamado de “teorema de Coase", derivado da demonstração dada pelo economista Ronald Coase de que quaisquer tipos de problemas ambientais são consequência da indefinição dos direitos de propriedade (COASE, 1960). Embora no Brasil não exista propriamente uma indefinição dos direitos de propriedade, pois os Art. 20 e Art. 26 da Constituição Federal (BRASIL, 1988) estabelecem o domínio da União e dos Estados sobre a maioria dos recursos naturais tidos como bens públicos, o exercício da titularidade desses bens e a execução de mecanismos de proteção ambiental são limitados pelas dificuldades impostas pelo amplo território, pela diversidade de biomas e ecossistemas, pela vasta quantidade de informaçóes necessárias para estabelecer medidas de controle e pelos custos administrativos envolvidos na aplicaçáo eficaz de instrumentos regulatórios diretos determinados pela política comando-e-controle (RIBEIRO e LANNA, 2001). Frente às dificuldades do emprego de mecanismos de gestáo orientados para o controle, a abordagem baseada em incentivos econômicos candidata-se como alternativa possível para promoção da qualidade ambiental, principalmente em vista das desigualdades regionais verificadas no Brasil entre os Estados federados e também no âmbito intra-estadual. Em particular, no Estado de Santa Catarina verificou-se que as medidas puramente jurídicas poderiam causar mais problemas do que soluçóes no seu meio rural, que é caracterizado por agricultura familiar praticada em pequenas lavouras ou criaçóes e por relevo acidentado em grande parte das terras agrícolas (MARTINI e TRENTINI, 2011). Nesse cenário, a Lei No 15.133 instituiu em 2010 a Política Estadual de Serviços Ambientais (SANTA CATARINA, 2010), que regulamenta o Programa Estadual de Pagamento por Serviços Ambientais (PEPSA) e estabelece outras providências. O PEPSA suporta três subprogramas: (I) Subprograma Unidades de Conservação, (II) Subprograma Formaçôes Vegetais e (III) Subprograma Água. Posteriormente, o dispositivo PSA foi incluído na Lei Federal No 12.651 de 25/05/2012, mais conhecida como Novo Código Florestal (BRASIL, 2012).

Como destacado por Thomé (2014, p.323), o caput do artigo 41 do Novo Código Florestal dispóe que o Poder Executivo Federal está autorizado a instituir programa de apoio e incentivo à conservaçáo do meio ambiente, bem como para adoção de tecnologias e boas práticas que conciliem produtividade agropecuária e florestal com a redução de impactos ambientais. E uma das linhas de açáo do programa catarinense baseia-se justamente na definição de pagamento por serviços ambientais como "a retribuição, monetária ou 
não, referente às atividades humanas de preservaçáo, manutenção, proteção, restabelecimento e melhoria dos ecossistemas que geram serviços ambientais (...)"(SANTA CATARINA, 2010, Art. 3 II).

Como tarefa auxiliar, a implantação do PEPSA em Santa Catarina ou de programas similares em outras regiōes requerem a identificação dos principais serviços ambientais que podem ser associados às unidades territoriais de interesse, que eventualmente podem ser demarcadas pelas suas principais bacias hidrográficas. No entanto, os estudos de caso do PSA no Brasil normalmente tratam de experiências localizadas e com serviços ambientais específicos. Em Santos et al. (2012, p.22) verifica-se que a tipologia de serviços é listada entre os nove componentes usados para análise dos regimes legais documentados, porém não há nesse estudo uma síntese dos serviços mais frequentes nos casos estudados. Da mesma forma, Pagiola et al. (2013) fazem uma extensa revisão de casos da aplicação do PSA no Brasil, mas neste estudo os autores destacam mais as açóes empreendidas e seus resultados do que a caracterizaçáo dos tipos de serviços. Por outro lado, Guedes e Seehusen (2011) classificam e caracterizam os serviços ambientais de uma forma similar a que será adotada neste trabalho, uma vez que ambos os estudos baseiam-se nas indicaçôes e sugestôes estabelecidas no Millennium Ecosystem Assessment (2005). Além disso, no trabalho de Guedes e Seehusen (2011) pode-se verificar a preocupação em destacar os serviços ambientais de provisão de alimentos, fibras e combustíveis, os quais normalmente são negligenciados em outros estudos, que são mais focados nos serviços de regulação e, às vezes, nos serviços culturais.

Dessa forma, como um passo julgado necessário às tarefas de promoção do uso do instrumento PSA, o objetivo central deste trabalho foi estruturar um quadro sinótico dos serviços ambientais mais relevantes distribuídos nas principais bacias hidrográficas do Estado de Santa Catarina. A identificação dos serviços ambientais em nível de bacia hidrográfica como se propóe aqui pode servir como orientaçáo aos programas de implantação do PSA, bem como pode proporcionar subsídios para a gestão de recursos naturais em áreas com usos da terra que conflitam com a proteção ambiental.
O trabalho a seguir contém duas partes principais. No item Material e Métodos faz-se a identificação das categorias e subcategorias de serviços ambientais mais relevantes para Santa Catarina e elabora-se uma distribuição dos serviços ao longo das principais bacias hidrográficas catarinenses. Além disso, nesse item apresenta-se a metodologia empregada para ordenar o grau de importância de cada categoria ou subcategoria de serviço ambiental. No item Resultados e Discussão, apresentam-se indicadores para caracterizar as principais bacias hidrográficas de Santa Catarina, os quadros sinóticos com a distribuiçáo por bacia dos serviços ambientais e uma primeira aproximaçáo da importância relativa desses serviços no contexto catarinense.

\section{MATERIAL E MÉTODOS}

\section{Identificação dos tipos de serviços ambientais}

Em 2000, a Organização das Naçóes Unidas criou um comitê internacional com representantes das diversas esferas de tomada de decisáo para avaliar as consequências das mudanças nos ecossistemas sobre o bem estar humano e estabelecer bases científicas para as açóes necessárias à promoção da conservação e uso sustentável dos ecossistemas. Uma síntese dos relatórios desses representantes foi publicada no documento Millennium Ecosystem Assessment (2005), nome pelo qual passou a ser denominado esse comitê.

Nos documentos do Millennium Ecosystem Assessment, os serviços ambientais foram enquadrados em quatro grupos abrangentes:

1. Serviços de suporte ou de base, constituídos por funçôes amplas como ciclagem global de nutrientes, formação do solo e produção primária;

2. Serviços de provisão, como produção de alimentos, captação de água doce, produção de madeira e fibras, carvão mineral etc.;

3. Serviços de regulação, como controle de inundaçóes, purificação da água, regulação climática e controle de doenças; e

4. Serviços culturais, representados principalmente por valores espirituais, educacionais, estéticos e recreacionais. 
Em termos regionais, como os serviços de suporte ou de base e os serviços de regulação muitas vezes se confundem, neste trabalho optou-se por agregar os serviços de suporte ou de base dentro dos serviços de regulação.

Por sua vez, cada um dos três ou quatro grandes grupos de serviços pode ser subdividido em categorias e subcategorias que especificam os tipos de serviços ambientais disponíveis em dada região. Considerando as particularidades de Santa Catarina e os dados qualitativos e quantitativos disponíveis em diversas fontes, no trabalho foram identificadas 15 categorias de serviços em três grupos principais, a saber:

1. Serviços de provisão: alimentos; florestas; recursos hídricos; minerais e rochas;

2. Serviços de regulação: qualidade do ar; regulação climática; controle da erosão; bioassimilação de efluentes; purificação da água; regulação de desastres naturais; regulação ecossistêmica; dinâmica costeira;

3. Serviços culturais: valores culturais e religiosos; valores estéticos; recreação e ecoturismo.

Para os serviços de provisão julgou-se necessário criar subcategorias para delimitar de forma mais adequada cada um dos serviços disponíveis. Foram adotadas as seguintes subdivisóes:

- Provisão de alimentos: área total com produção vegetal, área com produção vegetal em lavouras permanentes, área com produção vegetal em lavouras temporárias, produção animal total, produção animal - suínos e extrativismo;

- Provisão de florestas: madeira, lenha/celulose, carvão vegetal;

- Provisão de recursos hídricos: abastecimento público, irrigação, geração de energia elétrica e navegação;

- Provisão de minerais e rochas: carvão mineral, indústria cerâmica; construção civil.

\section{Serviços ambientais em bacias hidrográficas catarinenses}

Dada a estreita relação de grande parte dos ecossistemas e agroecossistemas com os corpos hídricos, a bacia hidrográfica destaca-se como opção natural para distribuição geográfica das diferentes categorias de serviços ambientais. Podem ser empregados outros critérios de agrupamento, como divisóes administrativas, níveis hierárquicos da ecologia e geossistemas. No primeiro caso, os limites municipais e regionais geralmente náo coincidem com os limites dos ecossistemas/agroecossistemas de interesse, o que traz inconvenientes práticos no momento da distribuição espacial dos serviços ambientais. Por sua vez, níveis ecológicos como biomas e paisagens podem ser ou muito extensos ou de difícil delimitação, enquanto que os geossistemas ainda são pouco difundidos como alternativa para subdivisão do espaço físico.

A distribuição dos serviços ambientais por bacia hidrográfica também permite a escolha da escala mais adequada para subdivisão territorial, sendo possível escolher desde microbacias rurais até bacias com dimensôes regionais. Para efeito do planejamento, gestão e gerenciamento dos seus recursos hídricos, Santa Catarina adotou uma subdivisão do território em dez regióes hidrográficas, que englobam vinte e duas bacias hidrográficas bem definidas e um conjunto de sub-bacias indeterminadas que drenam para o rio Iguaçu, no norte do Estado (SANTA CATARINA, 1998). A Figura 1 mostra a distribuição das bacias hidrográficas no território catarinense utilizada neste trabalho. As bacias mais continentais correspondem aos afluentes do rio Uruguai e rio Iguaçu e as litorâneas são agrupadas no que geralmente denomina-se de Vertente Atlântica, que reúne bacias que desaguam diretamente no Oceano Atlântico.

Como os dados empregados neste trabalho para definir os principais serviços ambientais geralmente tiveram como referência o nome dos municípios catarinenses, cada um deles foi associado a uma das bacias hidrográficas mostradas na Figura 1. Empregou-se a localização geográfica da sede municipal como critério de associação. Além disso, municípios com áreas insulares significativas, como é o caso de Florianópolis e São Francisco do Sul, foram incluídos nas bacias hidrográficas regionalmente mais importantes.

Para identificação por bacia dos principais serviços de provisão de alimentos, florestas e extrativismo foram empregados os seguintes dados:

- a produçáo vegetal baseou-se no levantamento da Produção Agrícola Municipal 2015 do 


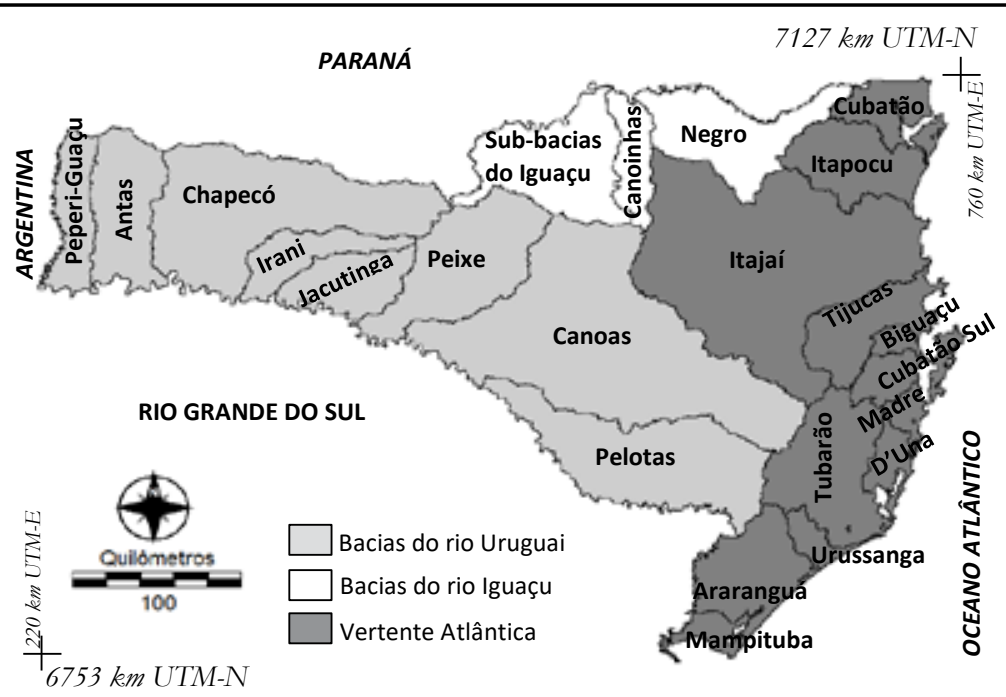

Figura 1- Principais bacias hidrográficas do Estado de Santa Catarina

IBGE (2016a) e IBGE (2016b), que registra as áreas cultivadas com lavouras temporárias e com lavouras permanentes, respectivamente;

- a produção animal foi obtida na Pesquisa Pecuária Municipal 2015 do IBGE (2016c). Totalizou-se o número de cabeças das criaçóes em geral e da produção de suínos;

- a produçáo florestal e extrativismo foram compilados na Produção da Extração Vegetal e da Silvicultura 2015 do IBGE (2016d). Para florestas, foram consideradas a produção de madeira em toras para laminados $\left(\mathrm{m}^{3}\right)$, a produção de celulose e lenha $\left(\mathrm{m}^{3}\right)$ e produção de carvão vegetal (toneladas); no item extrativismo, considerou-se a produção total de itens alimentícios (toneladas), que foi incluída no grupo provisão de alimentos.

Para provisão recursos hídricos, foram consideradas a população total de cada bacia (abastecimento humano), a área irrigada e a capacidade de geração de hidroeletricidade instalada a partir das seguintes fontes:

- a população total de cada bacia foi computada a partir da população dos municípios que a compóe com base no Censo Demográfico de 2010 (IBGE, 2016);
- a área irrigada foi obtida no Censo Agropecuário 2006 (IBGE, 2016f);

- a capacidade de geração de energia hidrelétrica em operação $(\mathrm{kW})$ em cada bacia foi obtida no Banco de Informaçóes de Geração disponível na Agência Nacional de Energia Elétrica (ANEEL, 2016).

No cômputo dos serviços de provisão de minérios e rochas considerou-se a produção de carvão mineral, de minérios para a indústria cerâmica e de materiais diversos para construçáo civil. Os dados para esses itens foram obtidos em FIESC (2014) e referem-se ao período 2010-2012.

Para os serviços de regulação foram considerados os seguintes critérios e dados:

- a erosão agrícola foi ponderada com base na relevância da produção agrícola na bacia hidrográfica (provisão total de alimentos) e a erosão urbana tomou como base o grau de urbanização da bacia, determinado pela população urbana obtida no Censo Demográfico de 2010 (IBGE, 2016e).

- a bioassimilação de efluentes considerou a concentração de suínos na bacia - dada pela quantidade de suínos obtida na categoria produção animal - e a densidade popu- 
lacional em cada bacia (habitantes $/ \mathrm{km}^{2}$ ), obtida pela divisão da população total da bacia (IBGE, 2016e) pela sua área. A seleção da concentração de suínos como critério na categoria bioassimilaçáo decorre do fato de a suinocultura ser a principal fonte potencial de efluentes rurais em Santa Catarina;

- a purificação de água baseou-se na necessidade de abastecimento humano, aproximada pela população total da bacia (IBGE, 2016e);

- como forma de ponderar a regulação de desastres naturais, levou-se em conta a frequência de estiagens, de inundaçóes e de movimentos de massa em cada bacia a partir de dados contidos no Atlas Brasileiro de Desastres Naturais 1991-2010 (UFSC, 2011);

- uma vez que serviços indiretos como polinização, preservação da biodiversidade, regulação de doenças e pragas agrícolas englobados na "regulação ecossistêmica" são atendidos por áreas ambientalmente protegidas, para avaliar o nível de importância desta categoria levou-se em conta a fração que cada bacia possui do total de Áreas de Proteção Ambiental federais e Unidades de Conservaçáo estaduais no território catarinense (MMA, 2016);

- para dinâmica costeira, a importância de cada bacia foi ponderada pela respectiva proporção ocupada na região hidrográfica Vertente Atlântica.

Os serviços de regulação qualidade do ar e regulação climática são listados devido ao potencial de inclusão em programas de pagamento por serviços ambientais. Como não existem dados quantitativos para estabelecer seus níveis de importância, os campos referentes a cada bacia náo foram preenchidos.

Em Santa Catarina, os serviços culturais têm reconhecida importância socioeconômica. Embora alguns desses serviços possam ser quantificados, principalmente na categoria de recreação e ecoturismo, as bases de dados disponíveis não permitem uma distribuição adequada por bacia hidrográfica. Além disso, serviços associados a valores culturais, religiosos e estéticos revestem-se de alta subjetividade. Dessa forma, neste trabalho optou-se apenas por listar os serviços culturais e não se atribuiu a eles níveis específicos de importância ambiental.
Para permitir uma comparação dos serviços ambientais entre as bacias, estabeleceu-se uma gradação da importância ambiental de cada serviço em cinco níveis. Para as categorias Alimentos e Florestas, utilizou-se o critério de atribuir os níveis 1, 2, 3, 4 e 5 ao primeiro, segundo, terceiro, quarto e quinto quintil, respectivamente. Não foram atribuídos níveis de importância ambiental quando uma bacia não apresenta determinado serviço ou ele está presente em níveis insignificantes. Na categoria Recursos Hídricos, para as subcategorias abastecimento, irrigaçáo e hidroeletricidade utilizou-se o mesmo procedimento dos grupos Alimentos e Florestas. À subcategoria navegação, que apresenta importância relativa apenas para a bacia do rio Itajaí, atribuiu-se o nível 1 somente como forma de indicar a presença desse serviço na bacia. Na categoria Minérios e Rochas, às subcategorias carvão mineral e indústria cerâmica foram atribuídos apenas dois níveis de importância, uma vez que tais serviços são relevantes apenas para três e quatro bacias, respectivamente. Ainda dentro dessa categoria, a subcategoria construção civil foi hierarquizada entre bacias de acordo com a população residente na área urbana, variável indicativa do uso de materiais em edificaçóes, pavimentos e outras obras.

Para obtenção de um nível de importância agregado para cada uma das categorias gerais de provisão adotou-se o seguinte procedimento: inicialmente calculou-se por bacia a média aritmética dos níveis de importância ambiental atribuídos às diferentes subcategorias; a partir do novo conjunto de dados formado pelas médias das categorias, atribuíram-se os níveis 1, 2, 3, 4 e 5 para os valores situados no $1^{\circ}$, $2^{\circ}, 3^{\circ}, 4^{\circ}$ e $5^{\circ}$ quintil, respectivamente. Para obtenção das médias, na categoria Alimentos empregou-se os níveis de importância ambiental das subcategorias "área total com produção vegetal", "produção animal total" e "extrativismo"; para Recursos Hídricos, as médias foram obtidas excluindo-se a subcategoria "navegação"; para Florestas e Minérios/Rochas as médias foram calculadas com base nas respectivas subcategorias que as compóem.

$\mathrm{Na}$ atribuição de níveis de importância ambiental para as categorias de serviços de regulação foram adotados procedimentos similares aos usados nas subcategorias dos serviços de provisão, isto é, os dados quantitativos foram distribuídos em cinco níveis de acordo com distribuição de valores nos quintis. 


\section{RESULTADOS E DISCUSSÃO}

O Quadro 1 apresenta a área relativa ocupada pelas principais bacias hidrográficas de Santa Catarina e uma síntese de indicadores demográficos, fundiários, de renda e de desenvolvimento. Comparando-se as três regióes hidrográficas do Estado, cerca da metade da área e do número de municípios situa-se nas bacias afluentes do rio Uruguai. Contudo, cerca de $68 \%$ da população e $72 \%$ do Produto Interno Bruto (PIB) estadual situam-se nas bacias que compóe a Vertente Atlântica, principalmente nas bacias do rio Cubatáo Norte, Itapocu, Itajaí e Cubatáo Sul. As bacias que drenam para o Iguaçu tem expressão menor nesses indicadores. Em conjunto, as duas maiores bacias catarinenses, do rio Canoas e do rio Itajaí, constituem quase um terço da área total do Estado e ao redor de um quarto dos municípios. No entanto, essas bacias apresentam marcantes diferenças na população total residente, na densidade populacional, no PIB total e no PIB per capita, pois os índices são bem mais elevados na bacia do Itajaí do que na bacia do Canoas. Embora o PIB per capita apresente diferenças expressivas entre as bacias, o Índice de Desenvolvimento Humano Municipal (IDHM) tem variaçóes menos acentuadas. Destaque-se que mais de $75 \%$ dos municípios de Santa Catarina têm IDHM considerado alto (entre 0,700-0,799) e onze deles apresentaram em 2010 IDHM muito alto (acima de 0,8 ). No conjunto, apenas nas bacias do Canoas e do Pelotas e nas Sub-bacias do Iguaçu o IDHM médio apresenta valores menores do que 0,7 .

Muitos dos indicadores do Quadro 1 estão diretamente relacionados com a área da bacia, porém a população e o PIB mais elevado na Vertente Atlântica também estão relacionados ao contexto histórico da ocupação territorial ter iniciado a partir do litoral, aos fluxos migratórios e à concentração atual de atividades industriais, portuárias e administrativas. Na região hidrológica do rio Uruguai, a bacia do rio Chapecó destaca-se das demais pelo maior PIB total e per capita. Em parte isso pode ser explicado pelo tamanho da bacia, uma vez que ela é a segunda maior da região e a terceira do Estado, mas fatores como produção agropecuária, concentração de agroindústrias e a geração de energia elétrica contribuem para índices mais elevados do que os registrados nas bacias do entorno.
Com relação à estrutura fundiária, em Santa Catarina a maioria dos estabelecimentos rurais possui áreas inferiores a 50 hectares e em mais de $85 \%$ dos estabelecimentos pratica-se agricultura familiar. Em virtude da pequena área média dos estabelecimentos rurais, as atividades agropecuárias normalmente são caracterizadas por uso intensivo de insumos externos à propriedade, como fertilizantes e agrotóxicos, pela criação de animais em confinamento e pelo uso de terras em situações topográficas desfavoráveis.

Os grupos e categorias de serviços ambientais mais relevantes identificados nas principais bacias hidrográficas catarinenses são mostrados no Quadro 2 , no qual apresenta-se também uma primeira aproximação do grau de importância relativa das categorias para cada uma das bacias.

Em termos gerais, para os serviços de provisão a maioria das bacias do rio Uruguai apresenta um nível de importância 4 ou 5 nas categorias de Alimentos e Florestas, demonstrando a forte vocação do meio-oeste, oeste e extremo-oeste catarinense na agropecuária e silvicultura (Figuras 2a e 2b). Nesse aspecto, pode-se computar que aproximadamente $32 \%$ da população dessas bacias reside no meio rural, enquanto a média estadual é de 23\% (Quadro 1). Nessa região hidrográfica pode-se também observar que as atividades de produção agrícola ocorrem sobretudo em estabelecimentos rurais com área média inferior a 30 hectares, com exceção das bacias do rios Canoas e Pelotas, onde há maior número de propriedades relativamente grandes (acima de 100 hectares), ocupadas com silvicultura, fruticultura e pecuária extensiva. Embora com marcada concentração nas bacias do rio Uruguai, os serviços de provisão de alimentos e florestas também são relativamente importantes nas bacias do rio Iguaçu e nas bacias do Itajaí, Tijucas e Araranguá, situadas na Vertente Atlântica (Figuras $2 \mathrm{a}$ e $2 \mathrm{~b})$.

Pela metodologia empregada neste trabalho, os serviços de provisão de Recursos Hídricos têm estreita relação com a demanda de água para abastecimento público e irrigação e com a capacidade instalada de geração de hidroeletricidade. Dessa forma, os níveis de importância ambiental atribuídos a essa categoria no Quadro 2 e Figura 2c refletem o tamanho da população - casos típicos das bacias dos rios Cubatão Norte, Itapocu, Itajaí e Cubatão Sul -, a geração de energia elétrica (Canoas e Peixe) e a captação de água 


\begin{tabular}{|c|c|c|c|c|c|c|c|c|c|c|c|c|c|c|}
\hline & eqnıłdurew o!y & $\stackrel{\infty}{\infty}$ & o & $\hat{m}$ & \begin{tabular}{|l|}
$\infty$ \\
$\infty^{\circ}$ \\
$\infty^{\prime}$
\end{tabular} & $\frac{N}{\check{z}}$ & in & $\stackrel{\circ}{m}$ & 伿 & 요 & $\stackrel{\infty}{\sim}$ & HG & $008^{\circ} \varepsilon$ & E. \\
\hline & ẹnbuesed $\forall$ o!̣ & $\stackrel{\infty}{m}$ & $\stackrel{\circ}{\circ}$ & 㞻 & $\stackrel{m}{R}$ & $\widehat{\tilde{N}}$ & 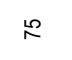 & $\hat{\infty}$ & $\stackrel{?}{?}$ & ి্ & $\hat{\sim}$ & $\varepsilon+\varepsilon^{\prime} 9$ & $006 \triangleright \tau$ & $\mid \begin{array}{l} \pm \\
0 \\
0\end{array}$ \\
\hline & ébuessnın o!y & $\stackrel{\infty}{0}$ & 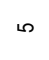 & $\bar{N}$ & $\tilde{\tilde{z}}$ & $\stackrel{\infty}{\sim}$ & ఇ్ల & $\stackrel{m}{m}$ & $\hat{y}$ & $\Xi$ & $\stackrel{\circ}{m}$ & $18 t^{\circ} \mathrm{L}$ & $00 \angle ' 8 z$ & $\begin{array}{l}0 \\
0 \\
0\end{array}$ \\
\hline & eun.a oly & $\stackrel{\circ}{=}$ & $m$ & $\stackrel{0}{\circ}$ & \begin{tabular}{c}
0 \\
\multirow{\infty}{*}{} \\
$\infty$
\end{tabular} & $\begin{array}{l}0 \\
\infty \\
\infty\end{array}$ & 은 & $\stackrel{\circ}{\circ}$ & ా্ల & $\approx$ & $\stackrel{\Xi}{\leftarrow}$ & $\angle E L^{\prime} \cdot$ & $008 \cdot 9 l$ & ֶֻ. \\
\hline & opseqn & is & $\stackrel{\infty}{-}$ & $\stackrel{\tilde{N}}{N}$ & $\begin{array}{l}\tilde{n} \\
\tilde{2}\end{array}$ & $\stackrel{\infty}{\sim} \underset{\sim}{\sim}$ & 落 & $\stackrel{n}{=}$ & ๙ & 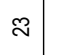 & $\stackrel{\infty}{\infty}$ & $6+t t^{2} L$ & 00062 & $\begin{array}{l}\stackrel{n}{2} \\
0 \\
0\end{array}$ \\
\hline 囷 & ә.рек ep o!ly & $\stackrel{0}{\circ}$ & $\sim$ & $\stackrel{\sim}{\sim}$ & $\bar{\infty}$ & $\begin{array}{l}\stackrel{\infty}{\infty} \\
\stackrel{\infty}{\infty}\end{array}$ & $\mathscr{q}$ & 20 & $\neq$ & $\stackrel{\sim}{\sim}$ & $\stackrel{+}{0}$ & IEG & $00 t^{\prime} l z$ & 悐 \\
\hline 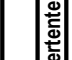 & Ins oejegno oly & $\stackrel{n}{=}$ & 0 & $\stackrel{\infty}{2}$ & $\begin{array}{l}m \\
8 \\
8\end{array}$ & $\widehat{m}$ & $\bar{\delta}$ & $\hat{\sim}$ & $\hat{m}$ & 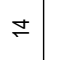 & $\stackrel{m}{\sim}$ & SLL $\angle Z$ & $000^{\prime} \downarrow \varepsilon$ & $\stackrel{\infty}{\infty}$ \\
\hline & nśenбీ!g ọ̣ & $\stackrel{t}{\circ}$ & $\sigma$ & $\stackrel{\circ}{\circ}$ & $\mid \begin{array}{l}0 \\
0 \\
\infty \\
1\end{array}$ & $\stackrel{\vec{m}}{\stackrel{m}{\rightleftarrows}}$ & 芯 & $\approx$ & স্ল & \pm & $\stackrel{\sim}{i}$ & $\angle 8 Z^{\prime} Z$ & $008 \mathrm{lZ}$ & 芯 \\
\hline & seon!! 1 o! & $\stackrel{\circ}{m}$ & 은 & d & $\frac{m}{5}$ & $\hat{\infty}$ & $\infty$ & $\hat{\sim}$ & ลे & R & * & Sเt't & $00 L \angle L$ & $\begin{array}{l}\substack{2 \\
0 \\
0} \\
0\end{array}$ \\
\hline & 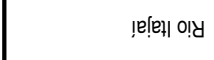 & ֻू & is & స్లి & \begin{tabular}{|c|} 
\\
\hdashline \\
$\infty$ \\
$\infty$
\end{tabular} & $\begin{array}{l}\text { 을 } \\
\text { if }\end{array}$ & $\infty$ & స్ల & $\frac{\infty}{\infty}$ & $\bar{n}$ & 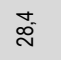 & $9 \varepsilon 6$ ૬ & $0080 t$ & 竞 \\
\hline : & noode| o! & $\stackrel{m}{m}$ & $\infty$ & $\bar{\infty}$ & \begin{tabular}{|l|}
0 \\
$\infty$ \\
$\infty$
\end{tabular} & $\stackrel{\circ}{\dddot{\Upsilon}}$ & \& & $\stackrel{\forall}{\forall}$ & 守 & $\stackrel{\infty}{q}$ & $\stackrel{\oplus}{\infty}$ & $98 \angle .91$ & $00 \angle 69$ & $\begin{array}{l}n \\
0 \\
0\end{array}$ \\
\hline 음 & 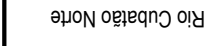 & $\stackrel{g}{=}$ & 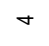 & 占 & \begin{tabular}{|l|}
0 \\
8 \\
8
\end{tabular} & $F$ & ల్ల & $\stackrel{\infty}{N}$ & i & $\hat{m}$ & $\bar{i}$ & $28 \varepsilon \cdot 92$ & $006+t$ & $\stackrel{0}{0}$ \\
\hline $\begin{array}{l}\frac{\pi}{0} \\
: \frac{\pi}{0} \\
\mathbb{m}\end{array}$ & 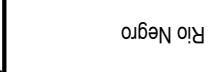 & $\stackrel{\llcorner}{\forall}$ & 0 & $\stackrel{\infty}{\sim}$ & $\begin{array}{l}0 \\
8 \\
\infty\end{array}$ & s. & $\bar{n}$ & $\stackrel{\circ}{\sim}$ & 尽 & i & $\tilde{0}$ & $6 Z 8^{\circ} \varepsilon$ & $009^{\circ} \mathrm{Ll}$ & 离 \\
\hline 흥 & seyuloueg oly & 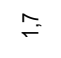 & $\sigma$ & $\infty$ & in & @i & ณ & $\stackrel{\circ}{+}$ & $\stackrel{m}{=}$ & F & $\stackrel{i}{i}$ & $89 \mathcal{L} Z$ & $00 Z^{\prime} \angle Z$ & E. \\
\hline & nઈ́en6| op sẹ̣eq-qns & $\overbrace{}^{m}$ & 0 & 8 & \begin{tabular}{l|}
0 \\
$\tilde{\tilde{O}}$
\end{tabular} & $\begin{array}{l} \pm \\
\dot{m}\end{array}$ & $\stackrel{m}{-}$ & $\stackrel{\circ}{\sim}$ & $\stackrel{\Xi}{\infty}$ & 요 & $\stackrel{\rho}{m}$ & $0 \angle L \cdot L$ & $0098 \mathrm{l}$ & $\ddot{\infty}$ \\
\hline & seł이커 이마 & $\hat{\imath}$ & $\circ$ & q & \begin{tabular}{|l|} 
\\
$\infty$ \\
$\infty$ \\
$\infty$
\end{tabular} & $\stackrel{0}{q}$ & 0 & ถึ & శั & ळ & $\overline{5}$ & $\varepsilon 6 L$ & $0096 \mathrm{l}$ & 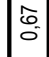 \\
\hline & seouej oly & $\underset{\sigma}{\stackrel{\Xi}{0}}$ & $\stackrel{\sim}{\sim}$ & $\stackrel{\infty}{\infty}$ & $\hat{\tilde{\infty}}$ & 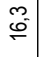 & $\Xi$ & $\stackrel{\infty}{\varnothing}$ & চ్ & $\infty$ & $\stackrel{\stackrel{\Xi}{\simeq}}{\simeq}$ & $\varepsilon 986$ & $001 \cdot 92$ & $:$ \\
\hline & әx!əd op oly & $\hat{\omega}$ & A & $\stackrel{\infty}{\sim}$ & $\mid$ & $\begin{array}{l}N^{2} \\
\stackrel{\infty}{\infty}\end{array}$ & 뇨 & $\stackrel{\mathscr{L}}{\simeq}$ & $\stackrel{\dddot{\vartheta}}{\forall}$ & ఇ్ & $\stackrel{\infty}{\circ}$ & $28 \nabla^{\prime} 6$ & $006^{\prime} \downarrow \mathcal{E}$ & $\begin{array}{l}n \\
0 \\
0\end{array}$ \\
\hline 훌 & é6unnoer ọy & $\stackrel{0}{i}$ & $F$ & $\stackrel{\infty}{=}$ & 吕 & 品 & $\stackrel{\circ}{\infty}$ & 2 & 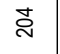 & $\stackrel{\Delta}{N}$ & $\begin{array}{l}L \\
\infty \\
\infty\end{array}$ & Z৪乙' & $00 L^{\prime} \cdot \varepsilon$ & $\begin{array}{l}\substack{n \\
0 \\
0} \\
0\end{array}$ \\
\hline : & प्र & $\bar{i}$ & $\infty$ & $\stackrel{\infty}{\sim}$ & \begin{tabular}{|l|}
$\hat{0}$ \\
$\infty$ \\
$\infty$
\end{tabular} & $\stackrel{m}{\stackrel{m}{\infty}}$ & $\stackrel{\text { 导 }}{\leftarrow}$ & $\tilde{\omega}_{0}^{\infty}$ & $\stackrel{\circ}{\circ}$ & $\infty$ & 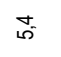 & 1096 & $006 \varepsilon \varepsilon$ & 竞 \\
\hline & ọəədeyว oly & के & 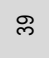 & i & $\begin{array}{l}\infty \\
0 \\
0 \\
1\end{array}$ & $\underbrace{2}$ & $\approx$ & $\overline{\mathrm{i}}$ & 응 & $\stackrel{2}{\sim}$ & $\hat{\bar{N}}$ & LSLOL & $00<8 t$ & N̂ \\
\hline & sefuy sep oly & $\stackrel{\leftrightarrow}{m}$ & $\bar{N}$ & 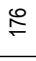 & $\begin{array}{l}\tilde{n} \\
\tilde{8} \\
\tilde{c}\end{array}$ & $\begin{array}{l}\infty \\
\infty \\
\infty \\
\infty\end{array}$ & $\stackrel{\infty}{q}$ & $\stackrel{\circ}{\infty}$ & ఖ্ల & $\bar{\sim}$ & $\hat{\emptyset}$ & $98 \mathrm{t}^{\prime} \mathrm{s}$ & $00 Z^{\prime} \downarrow \varepsilon$ & $\hat{N}$ \\
\hline & 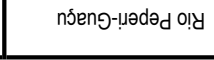 & $\stackrel{m}{N}$ & $\simeq$ & $\infty$ & 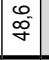 & $\frac{5}{5}$ & $\hat{m}$ & $\hat{\sigma}$ & $\stackrel{\infty}{\infty}$ & 요 & $\stackrel{\infty}{\infty}$ & $086^{\circ} \mathrm{L}$ & $008^{\prime} \downarrow \tau$ & 管 \\
\hline & $\begin{array}{l}\text { 흥 } \\
\text { 잏 } \\
\text { 을 }\end{array}$ & 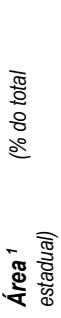 & 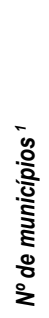 & 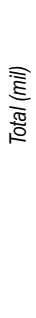 & $\mid$ & 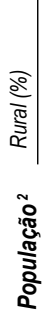 & 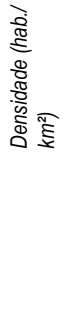 & 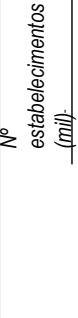 & 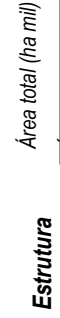 & 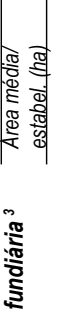 & 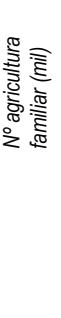 & 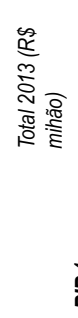 & 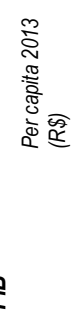 & 产 \\
\hline
\end{tabular}


a) Alimentos

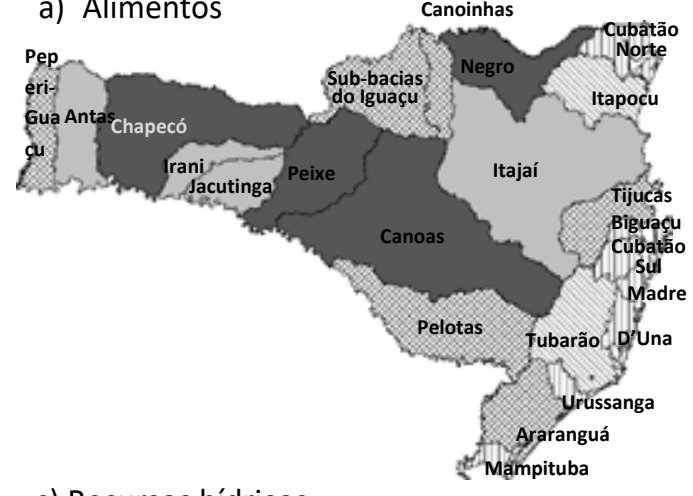

c) Recursos hídricos

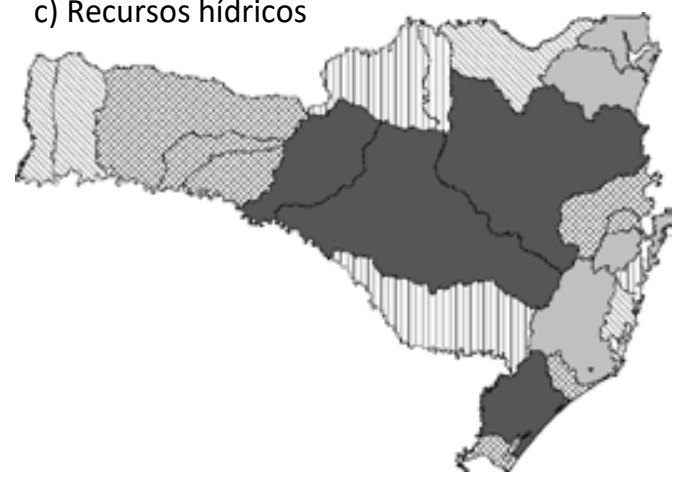

b) Florestas

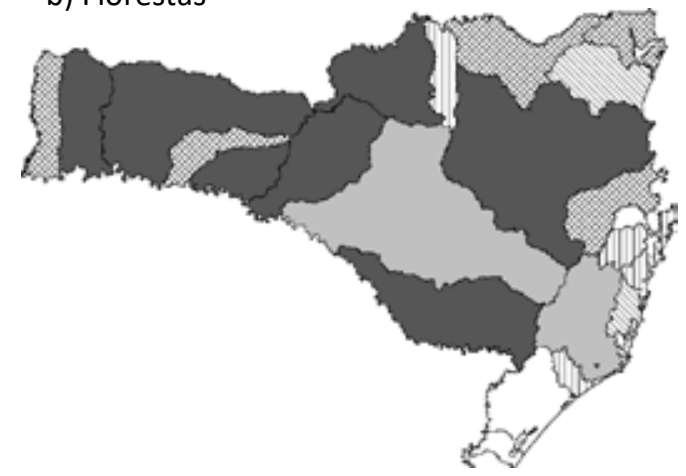

d) Minerais e Rochas

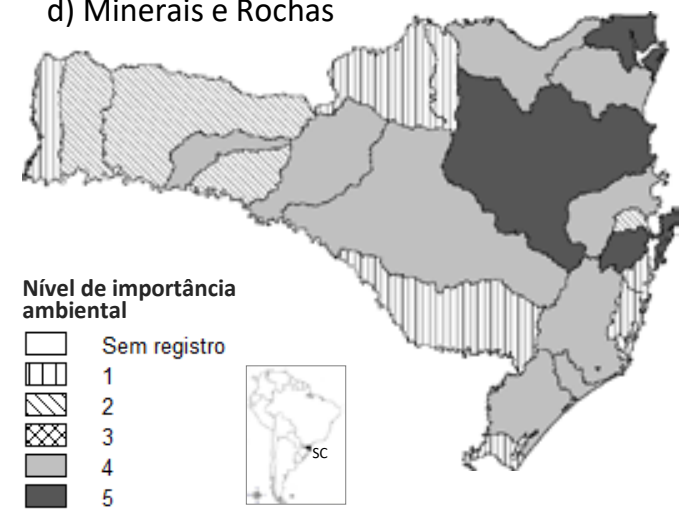

\section{Figura 2 - Distribuição espacial dos níveis de importância ambiental para os principais serviços ambientais de provisão gerados em Santa Catarina (SC)}

para irrigação nas bacias dos rios Tubarão, Araranguá e Itajaí.

Na categoria Minério e Rochas, o nível de importância ambiental está associado à população urbana da bacia - pois se entende que a demanda por materiais para obras de construção civil tem relação direta com o tamanho das cidades presentes na bacia - e às atividades relacionadas à exploração de minérios. Deve-se destacar que nesse item assumem importância as atividades de mineração de carvão e da indústria cerâmica em algumas bacias hidrográficas, como são os casos das do Araranguá, do Tijucas e do Urussanga (Figura 2d), que apesar de não estarem entre as mais populosas do Estado mostram níveis de importância relativamente altos nessa categoria de serviços.

Como esperado, os serviços de regulação indicados no Quadro 2 apresentam em geral estreita relação com o aprovisionamento de alimentos, de bens florestais, de recursos hídricos e de minerais/rochas, itens que resultam de atividades efetiva e potencialmente causadoras de impactos ambientais negativos. Além disso, existe uma associação evidente com o tamanho da população da bacia.

As bacias com significativa ocupação agrícola e/ ou alta concentração da população em áreas urbanas apresentaram os níveis mais altos de importância ambiental na categoria controle da erosão (Figura 3a), resultado que é coerente com os critérios empregados para ranquear as bacias. Contudo, deve-se ressaltar que a erosão agrícola e a erosão urbana estão relacionadas também a fatores que não foram ponderados no trabalho, como tipo e manejo do solo, relevo e formas de ocupação das áreas urbanas. A mesma cautela na análise do serviço controle da erosão deve 


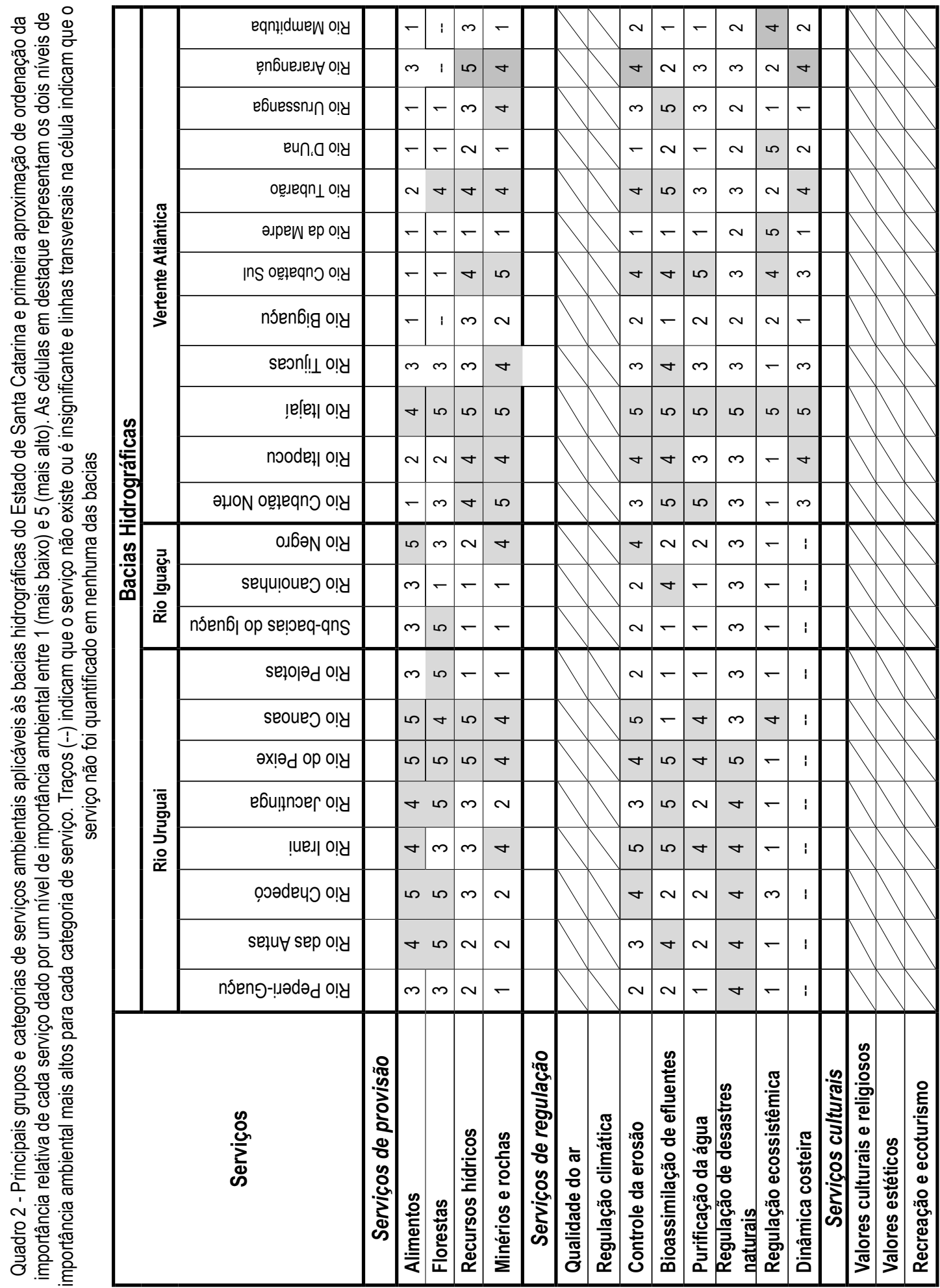


ser levada em conta na análise do serviço bioassimilação de efluentes, para o qual foram empregados na ponderação do nível de importância ambiental somente dois tipos de dados: a quantidade de suínos na bacia como indicador do potencial de efluentes rurais (Quadro 3) e a densidade populacional como indicador do potencial de lançamento de efluentes urbanos (Quadro 1). Portanto, deve-se considerar o nível de importância ambiental do serviço bioassimilação obtido neste trabalho como uma primeira aproximação (Figura 3b), reconhecendo-se que esse indicador pode ser melhorado à medida que estejam disponíveis dados sobre fatores como percentual de tratamento dos esgotos sanitários e quantidade de lançamentos de efluentes industriais no âmbito das principais bacias hidrográficas de interesse.

Dentre os serviços de regulação, geralmente o que tem apelo mais imediato para inclusão em um programa de pagamento por serviços ambientais (PSA) é o da purificação da água, tanto por ser essencial no abastecimento público como sua vinculação aos grupos de serviços de provisão e culturais. Como no trabalho utilizou-se a população para ponderar do nível de importância ambiental, as bacias que mostram níveis mais elevados nesse serviço são justamente aquelas com maior população residente (Figura 3c). Dessa forma, pode-se entender o nível de importância ambiental atribuído como um indicativo da demanda hídrica e do potencial de aplicação do PSA em dada bacia hidrográfica para fins de promoção do serviço de purificação da água.

Em termos importância nos serviços de regulação de desastres naturais, observa-se no Quadro 2 que predominam bacias afluentes do rio Uruguai dentre as mais destacadas (Figura 3d). Isso se deve principalmente à frequência mais alta de secas nas porções mais continentais de Santa Catarina, as quais ocasionam frustrações de safras e escassez hídrica para abastecimento humano e animal. $\mathrm{Na}$ bacia do Peixe, além dessas secas ocorrem periodicamente enchentes que ocasionam perdas econômicas significativas. Por outro lado, a bacia do Itajaí recebeu nível alto nesse quesito porque nela tem sido registrados ao longo do tempo eventos de enchentes e movimentos de massa (deslizamentos de terra) que acarretaram níveis altos de perdas materiais e humanas, com graves repercussões socioeconômicas nas regiões afetadas (UFSC, 2011). Pela própria expressão "desastres naturais", essa categoria de serviço apenas pode ser incluída de forma indireta em um programa de PSA, como as ensejadas na promoção de medidas não estruturais de controle de enchentes, movimentos de massa e estiagens, tais como diminuição de processos erosivos, redução de sedimentação, aumento da infiltração de água no solo, recomposição da cobertura vegetal em encostas íngremes e realocação de moradores de áreas de risco.

Como indicado brevemente na seção Material e Métodos, para a categoria regulação ecossistêmica considerou-se como elemento ponderador do nível de importância ambiental a fração existente em cada bacia hidrográfica do total de Áreas de Proteção Ambiental (APA) federais e Unidades de Conservação (UC) estaduais distribuídas no território catarinense. Como existe forte concentração de APAs e UCs nas bacias do Canoas, Itajaí, Cubatão Sul, da Madre, D'Una e Mampituba, a maioria das bacias catarinenses não possui áreas desse tipo ou a área é insignificante. Mesmo assim, no Quadro 2 e Figura 3e essas bacias receberam o nível 1 de importância ambiental pois elas comportam, pelo menos em parte, áreas de preservação permanente e reservas legais distribuídas nos imóveis rurais e em áreas ambientalmente protegidas de domínio particular e/ou municipal. Nesse ponto, deve-se observar o potencial para implantação do PSA em bacias com baixo nível de importância no serviço regulação ecossistêmica. Por exemplo, como o Subprograma Unidades de Conservação estabelecido no Artigo 10 da Lei No 15.133 (SANTA CATARINA, 2010) tem por finalidade gerir ações de pagamento para situações destinadas a "atender à diretriz de conservação ou recuperação de áreas prioritárias para fins de conservação da biodiversidade", tais áreas consideradas prioritárias podem ser selecionadas justamente com base na identificação das bacias com maiores necessidades de ampliação dos serviços de regulação ecossistêmica.

Devido à configuração hidrográfica catarinense, os serviços relativos à dinâmica costeira somente têm importância na Vertente Atlântica (Figura 3f). Neste trabalho, utilizou-se como elemento ponderador do nível de importância ambiental a percentagem da área total referente a cada bacia. Embora exista uma clara correlação positiva entre área da bacia, vazão e impactos na regiáo litorânea adjacente à foz do seu 


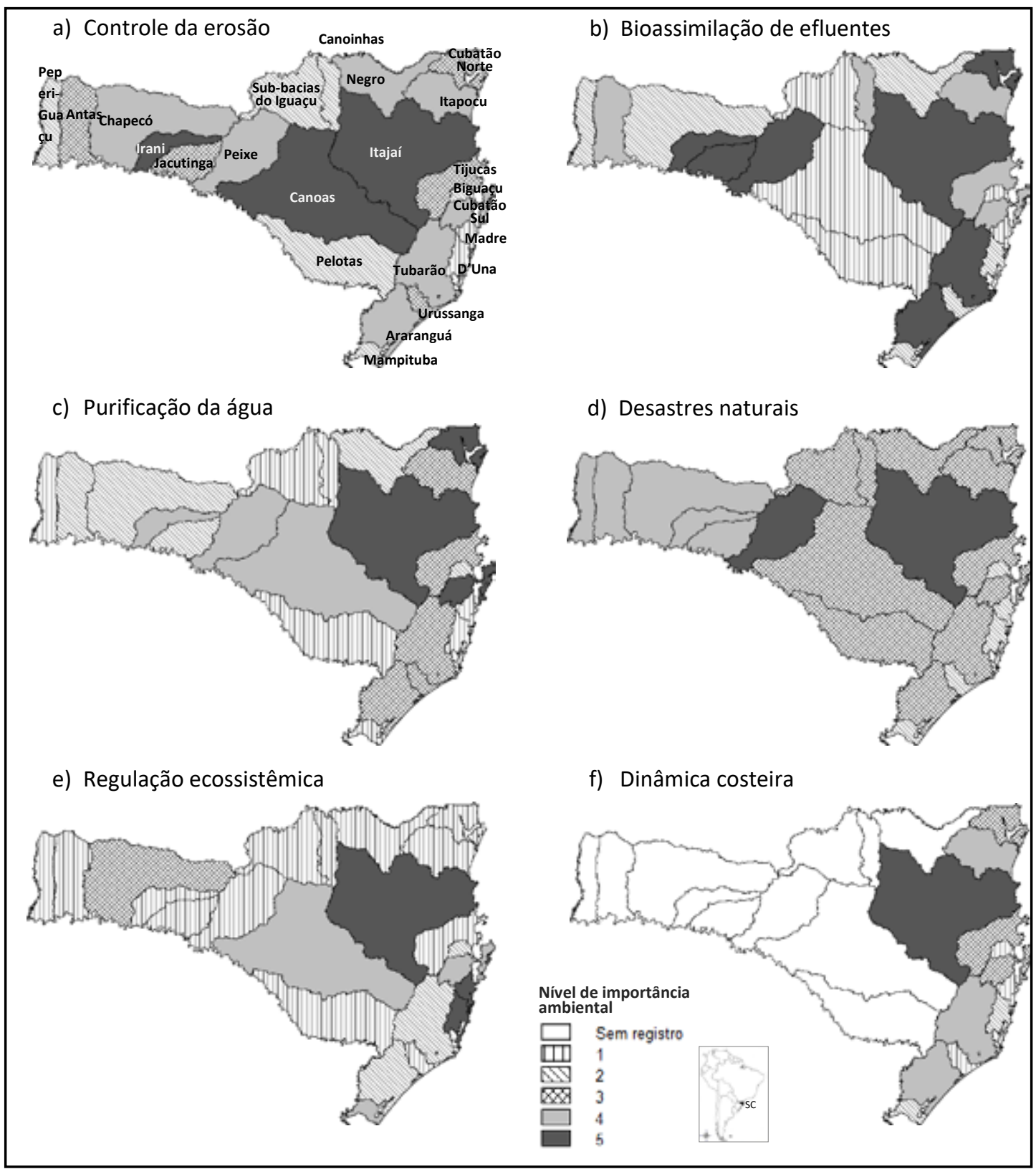

Figura 3 - Distribuição espacial dos níveis de importância ambiental para os principais serviços ambientais de regulação gerados em Santa Catarina

rio principal, não foram considerados aqui aspectos como presença de lagoas costeiras, que são corpos hídricos importantes na porção centro-sul do litoral catarinense, formação de manguezais (do município de Palhoça para o norte do Estado) e cordóes de dunas móveis e fixas presentes em trechos do litoral. Além disso, não foram levados em conta os principais portos marítimos de Santa Catarina (Itajaí-Navegantes, Imbituba e São Francisco do Sul). Dessa forma, o nível de importância ambiental relativo à dinâmica 


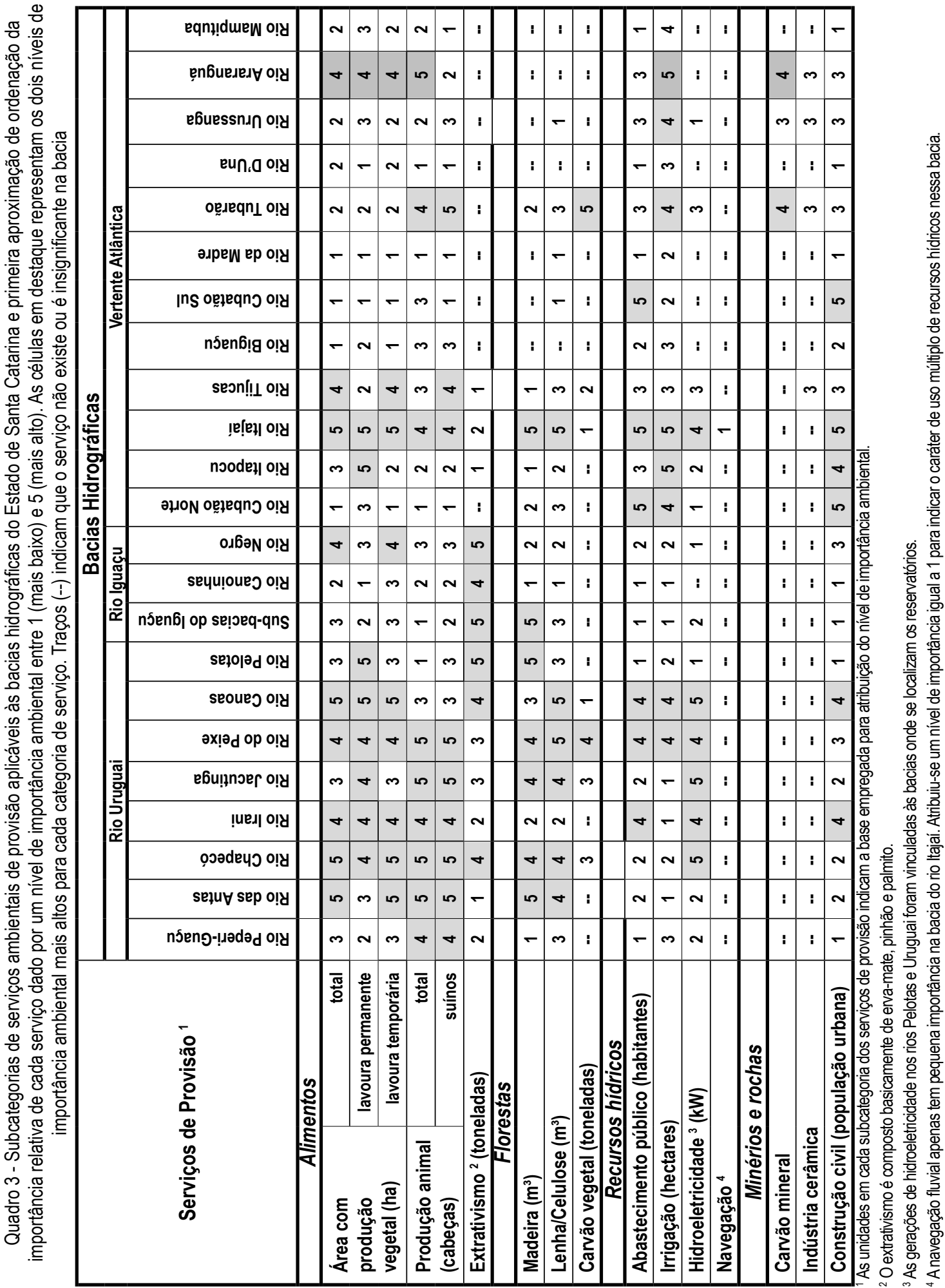


costeira mostrado no Quadro 2 e Figura 3 f tem caráter apenas ilustrativo.

Pela ausência de dados, os serviços de regulação da qualidade do ar e regulação climática não receberam no Quadro 2 um nível de importância ambiental por bacia. Do ponto de vista de qualidade do ar, em Santa Catarina tem sido registrados problemas no entorno dos distritos industriais nas bacias do Itajaí, Canoas, Itapocu e Cubatão Norte e nas regióes carboníferas. Porém, a compilação de relatos e a identificação do nível de importância ambiental ultrapassa o escopo deste trabalho. Da mesma forma, a questão da inserção das bacias catarinenses em programas voltados à promoção da redução de emissóes e/ou aumento da assimilação de carbono não foi considerada neste artigo.

Como nos casos dos serviços de regulação da qualidade do ar e de regulaçáo climática, para os serviços culturais não são indicados no Quadro 2 um nível de importância ambiental por bacia, justamente porque não foi possível obter ou ajustar dados representativos para cada uma das categoriais. Enquanto que os serviços de provisão e alguns serviços de regulação podem ser quantificados, seja pela produçáo ou pela demanda social de certo recurso ambiental, os ecossistemas ou paisagens associados a interesses estéticos, espirituais, religiosos e recreacionais normalmente náo são passíveis de serem representados por valores numéricos. Além disso, dado o caráter subjetivo desses serviços, ponderar o valor social a partir de interesses particulares é uma dificuldade metodológica importante na tarefa de enquadrá-los para fins de valoração econômica e para eventuais pagamentos. Não obstante tais dificuldades, estão disponíveis métodos desenvolvidos para quantificação de tais serviços. Por exemplo, Bateman et al. (2013) apresentam e discutem formas de medir o valor econômico de espaços para recreação, de espaços verdes urbanos e da diversidade de espécies de pássaros silvestres. Embora tais métodos não atendam todos os tipos de situaçóes, ao menos eles procuram indicar a importância relativa de determinados ecossistemas ou paisagens através da quantidade de pessoas que os visitam ou também pelo grau de diversidade biológica que apresentam. Considerando que esse é um campo de conhecimento ainda a ser explorado, os serviços culturais foram listados apenas para destacá-los como grupo relevante no conjunto total de serviços ambientais.
Por outro lado, a disponibilidade de dados quantitativos permite que os serviços de provisão possam ser mais bem discriminados utilizando-se subcategorias, como as que estão apresentadas no Quadro 3. Assim, os serviços de produção de alimentos podem ser subdivididos em produção vegetal, produção animal e extrativismo. Por sua vez, cada uma dessas subcategorias poderá receber tantos refinamentos quanto forem julgados pertinentes à região estudada. Neste trabalho, com base nos dados disponíveis em IBGE (2016) separou-se a produçáo vegetal em "lavoura permanente" (cultivos perenes) e "lavoura temporária" (cultivos anuais) e a produção animal em "produção total" (todos os rebanhos) e "produção de suínos" (neste caso, a separação foi usada para inferir o potencial de lançamento de efluentes rurais na bacia e compor o nível de importância do serviço de regulação bioassimilaçáo de efluentes). As demais categorias de serviços de provisão foram subdivididas de acordo com a relevância e a disponibilidade de dados quantitativos. A separação dos serviços de provisão em componentes individuais permite identificar relaçóes que permanecem ocultas quando se observam apenas as categorias mais gerais. Por exemplo, em virtude de sua grande área, tamanho da população e patamar alcançado em termos de desenvolvimento econômico, a bacia do rio Itajaí, da Vertente Atlântica, apresenta um nível alto ou muito alto de importância ambiental em todos os serviços de provisão e regulação mostrados no Quadro 2.

Porém, quando se olha o Quadro 3, verifica-se que nessa bacia a produçáo vegetal tem importância relativa maior do que a produçáo animal, enquanto que o extrativismo tem baixa relevância. Da mesma forma, na provisão de bens florestais destacam-se os itens madeira e lenha/celulose, mas a produção de carvão vegetal apresenta baixa importância nessa bacia.

Outro exemplo de relacionamento entre categorias de serviços ambientais que se pode retirar do Quadro 3 é a existente entre produção vegetal e irrigação. Note-se que na bacia do Araranguá existe nível alto de produção vegetal, tanto em lavouras permanentes como temporárias, bem como nível muito alto na provisão de recursos hídricos para irrigação. Tal fato se deve a grande área cultivada com arroz irrigado nessa bacia. Por outro lado, a bacia do rio Chapecó tem nível muito alto na produção vegetal em lavouras temporárias (cultivos anuais), porém baixo nível 
relativo no item irrigação, mostrando que o tipo de agricultura predominante na bacia é de sequeiro. Uma vez que a irrigação demanda grandes quantidades de água, existem evidentes inter-relaçóes entre as distintas subcategorias de serviços de provisão de recursos hídricos, bem como impactos significativos a serviços de regulação diretamente afetados, como purificação da água e bioassimilação de efluentes. Nesse aspecto, a identificação do nível de importância ambiental dos serviços ambientais pode auxiliar na aplicaçáo de instrumentos de gestão dos recursos hídricos estabelecidos na Lei 9.433, que instituiu a Política Nacional dos Recursos Hídricos (BRASIL, 1997), principalmente aqueles voltados para promoção do uso racional da água em bacias hidrográficas com problemas de disponibilidade hídrica quantitativa e/ ou qualitativa.

Finalmente, os Quadros 2 e 3 podem ser analisados verificando-se verticalmente quais serviços ambientais são mais relevantes para cada uma das bacias e quais os tipos de relacionamentos existentes entre eles. Para ilustrar esse tipo de análise, pode-se verificar na bacia do rio Chapecó que uma das categorias de serviço com importância relativa muito alta é a provisão de alimentos, que por sua vez afeta os serviços de regulação referentes ao controle de erosão - devido à produção agrícola centrada em culturas anuais (lavoura temporária) - e de bioassimilação dos efluentes, que resulta da produçáo animal em confinamento. Em contrapartida, pode-se verificar que nessa mesma bacia o serviço de provisão de recursos hídricos para geração de hidroeletricidade apresenta nível alto de importância. Considerando que as usinas hidrelétricas geralmente são diretamente afetadas pela quantidade de sedimentos e nutrientes afluentes aos seus reservatórios, a promoção de práticas de conservação do solo e manejo adequado de dejetos oriundos das criaçóes intensivas resulta em ganhos diretos ao setor de geração de energia. Nesse caso, verifica-se um claro vínculo entre as entidades beneficiadas e os agentes promotores da melhoria ambiental, fundamento do instrumento PSA.

Da mesma forma, a separação por bacia dos serviços ambientais em grupos, categorias e subcategorias e a respectiva atribuição de um nível de importância pode servir para identificação dos conflitos atuais e potenciais de uso dos recursos naturais, bem como para apoiar a tomada de decisão sobre aplicação de políticas públicas de gestão ambiental e implantação do instrumento PSA. Como exemplo, pode-se tomar o caso da bacia do rio Cubatão Sul (Quadro 3), que se destaca nos serviços de provisão de recursos hídricos para abastecimento e provisão de minérios e rochas para construção civil. Devido ao fato de ser uma das bacias que compóe a Regiáo Metropolitana de Florianópolis, segunda região mais populosa de Santa Catarina e a mais densamente povoada (Quadro1), existe uma clara dependência desses itens de provisão com os serviços associados ao controle da erosão, à bioassimilaçáo de efluentes, purificação da água, regulação de desastres naturais e regulação ecossistêmica. Nessa bacia em particular, a crescente demanda por água para abastecimento tem gerado conflitos com o uso agrícola das terras, principalmente em lavouras que utilizam sistemas de produção baseados no uso de agrotóxicos e fertilizantes minerais. Nesse ponto, destaca-se o potencial de introduçáo do PSA em locais críticos, principalmente com base no sistema que tem sido denominado de "produtor de água" (ANA, 2012), pois apesar de a bacia náo se caracterizar pelo provisionamento de alimentos, ainda sim apresenta uma significativa produção de hortigranjeiros distribuída em pequenas propriedades rurais que compóe o cinturão verde dessa região metropolitana.

\section{CONCLUSÕES}

A distribuição dos serviços ambientais mais relevantes nas principais regióes hidrográficas de Santa Catarina mostrou que os serviços de provisão são aqueles que podem ser mais bem definidos e quantificados em nível de bacia, uma vez que existem dados censitários e outros levantamentos para suportar a identificação e hierarquização do grau de importância de cada categoria ou subcategoria de serviço. De outra parte, os serviços de regulação podem ser caracterizados de forma indireta de acordo com os impactos esperados nos componentes ambientais em decorrência do uso do solo, dos recursos hídricos e geológicos e do lançamento de gases na atmosfera. Como tanto os serviços de provisão como os de regulação podem ser objeto de valoração econômica, existe potencial para implantação em Santa Catarina de instrumentos econômicos da classe do pagamento por serviços 
ambientais (PSA). Embora neste trabalho tenha se optado por não definir e hierarquizar por bacia os chamados "serviços culturais", deve-se ressaltar que esse grupo de serviços ambientais tem destaque em diversas regióes catarinenses com vocação turística, como é o caso de todo o litoral e do médio e baixo vale do rio Itajaí, e também podem ser incluídos nos sistema de PSA.

Finalmente, os quadros sinóticos de serviços ambientais para Santa Catarina obtidos no trabalho mostraram que as bacias hidrográficas que drenam para o rio Uruguai caracterizam-se principalmente como provedoras de alimentos e produtos florestais. Também se destacam nessas bacias os aproveitamentos hidroenergéticos de médio e pequeno porte. Por outro lado, as chamadas bacias do sudeste, que drenam diretamente para o Oceano Atlântico, caracterizam-se mais pelos serviços de regulação, principalmente porque nessas bacias predominam atividades industriais, portuárias e nelas concentram-se os maiores aglomerados urbanos de Santa Catarina.

\section{Referências}

ANA. Agência Nacional de Águas. Manual Operativo do Programa Produtor de Água. 2ª Edição. Brasilia: ANA, 2012.

ANEEL. Agência Nacional de Energia Elétrica. BIG - Banco de Geração de Informações. Capacidade de geração do Brasil. Disponivel em: <http:// http://www2.aneel.gov.br/aplicacoes/capacidadebrasil/capacidadebrasil.cfm>. Acesso em: 12.out.2016.

BATEMAN I.J., HARWOOD A.R., MACE G.M. et al. Bringing ecosystem services into economic decision-making: land use in the United Kingdom. Science 341, pp. 45-50, 2013.

BRASIL. Constituição (1988). Constituição da República Federativa do Brasil. Brasília, DF: Presidência da República, Casa Civil, Sub-Chefia para Assuntos Jurídicos. Disponivel em: <http://www.planalto.gov.br/ccivil_03/Constituicao/Constituicao.htm>. Acesso em: 07.out.2016.

Lei Federal No 9.433, de 8 de janeiro de 1997. Institui a Política Nacional de Recursos Hídricos e dá outras providências. Disponivel em: <http://www.planalto.gov.br/ccivil_03/leis/L9433.htm>. Acesso em: 25.out.2016.

. Lei Federal № 12.651, de 25 de maio de 2012. Dispõe sobre a proteção da vegetação nativa; altera as Leis nos 6.938 , de 31 de agosto de 1981, 9.393, de 19 de dezembro de 1996, e 11.428, de 22 de dezembro de 2006; revoga as Leis nos 4.771, de 15 de setembro de 1965, e 7.754, de 14 de abril de 1989, e a Medida Provisória no 2.166-67, de 24 de agosto de 2001; e dá outras providências. Disponivel em: http://www.planalto.gov.br/ccivil_03/_ato2011-2014/2012/lei//12651.htm>. Acesso em: 25.out.2016.

COASE R.H. The problem of social cost. Journal of Law and Economics 3, pp. 1-44, 1960.

CONSTANZA R., D'ARGE R., DE GROOT R. et al. The value of the world's ecosystem services and natural capital. Nature 387, p. 253-260, 1997.

FIESC. Federação das Indústrias do Estado de Santa Catarina. Santa Catarina em Dados: 2014/Unidade de Política Econômica e Industrial. - Florianópolis: FIESC, 2014.

IBGE. Instituto Brasileiro de Geografia e Estatística. Produção agrícola municipal 2015: área plantada, área colhida, quantidade produzida, rendimento médio e valor da produção das lavouras temporárias. Disponivel em: <http://www.sidra.ibge.gov.br/bda/tabela/listabl. asp?c=1612\&z=p\&o=30>. Acesso em: 10.out.2016a. 
. Instituto Brasileiro de Geografia e Estatística. Produção agrícola municipal 2015: área destinada à colheita, área colhida, quantidade produzida, rendimento médio e valor da produção das lavouras permanentes. Disponível em: <http://www.sidra.ibge.gov.br/bda/tabela/listabl. asp?c=1613\&z=p\&o=30>. Acesso em: 10.out.2016b.

. Instituto Brasileiro de Geografia e Estatística. Pesquisa pecuária municipal 2015: efetivo dos rebanhos, por tipo de rebanho. Disponivel em: <http://www.sidra.ibge.gov.br/bda/tabela/listabl.asp?c=3939\&z=p\&o=29>. Acesso em: 10.out.2016c.

. Instituto Brasileiro de Geografia e Estatística. Produção da extração vegetal e da silvicultura 2015: quantidade produzida e valor da produção. Disponivel em: <http://www.sidra.ibge.gov.br/bda/tabela/listabl.asp?c=289\&z=p\&o=31>. Acesso em: 10.out.2016d.

. Instituto Brasileiro de Geografia e Estatística. Censo demográfico 2010: população residente por situação de domicílio. Disponível em: $<h t t p: / / w w w . s i d r a . i b g e . g o v . b r / b d a / t a b e l a / l i s t a b l . a s p ? z=c d \& 0=6 \& i=P \& c=3145>$. Acesso em: 10.out.2016e.

Instituto Brasileiro de Geografia e Estatística. Censo agropecuário 2006: número de estabelecimentos agropecuários com uso de irrigação e área dos estabelecimentos por método utilizado para irrigação. Disponível em: <http://www.sidra.ibge.gov.br/bda/tabela/listabl. asp?c=855\&z=p\&o=2\&i=P>. Acesso em: 10.out.2016f.

. Instituto Brasileiro de Geografia e Estatística. Produto Interno Bruto dos Municípios 2010-2013. Disponível em: <http://www.ibge.gov. br/home/estatistica/economia/pibmunicipios/2010_2013/default_xls.shtm>. Acesso em: 10.out.2016g.

MARTINI L.C.P., TRENTINI É.C. Agricultura em zonas ripárias do sul do Brasil: conflitos de uso da terra e impactos nos recursos hídricos. Sociedade e Estado v 26, n 3, p.613-630, 2011.

MILLENNIUM ECOSYSTEM ASSESSMENT. Ecosystems and Human Well-being: Synthesis. Island Press, Washington, DC, 2005.

MMA. Ministério do Meio Ambiente. Cadastro Nacional de Unidades de Conservação. http://www.mma.gov.br/areas-protegidas/cadastro-nacional-de-ucs>. Acesso em: 18.mar.2016.

NAEEM S., INGRAM J.C., VARGAA. et al. Get the Science right when paying for nature's services. Science 347, pp. 1206-1207, 2015.

PAGIOLA, S., von GLEHN, H. C., TAFFARELLO, D. (Org.). Experiências de pagamentos por serviços ambientais no Brasil. - São Paulo: SMA/CBRN, 2013.

PNUD. Programa das Nações Unidas para o Desenvolvimento. Atlas do desenvolvimento humano no Brasil 2013. Disponível em: http://www. atlasbrasil.org.br/2013/pt/. Acesso em: 18.mar.2016.

RIBEIRO, M. M. R., LANNA, A. E. L. Instrumentos regulatórios e econômicos: aplicabilidade à gestão das águas e à bacia do rio Pirapama-PE. RBRH, v.6, n.4, 2001.

SANTACATARINA. Lei Estadual № 10.949, de 09 de novembro de 1998. Dispõe sobre a caracterização do Estado em dez Regiões Hidrográficas.

. Lei Estadual № 15.133, de 19 de janeiro de 2010. Institui a Política Estadual de Serviços Ambientais e regulamenta o Programa Estadual de Pagamento por Serviços Ambientais no Estado de Santa Catarina, instituído pela Lei $n^{0} 14.675$, de 2009, e estabelece outras providências.

SANTOS, P., BRITO, B., MASCHIETTO, F., OSÓRIO, G., MONZONI, M. (Org.). Marco regulatório sobre pagamentos por serviços ambientais no Brasil. - Belém, PA: IMAZON; FGV. CVces, 2012. 
Martini L.C. P. $\approx$ Serviços ambientais gerados nas principais bacias hidrográficas ...

THOMÉ R. Manual de direito ambiental. $4^{a}$ ed. Ed. JusPodivm. Salvador, BA, 2014.

UFSC. UNIVERSIDADE FEDERAL DE SANTA CATARINA. Centro Universitário de Estudos e Pesquisas sobre Desastres. Atlas brasileiro de desastres naturais 1991 a 2010: volume Santa Catarina. Florianópolis: CEPED UFSC, 2011.

Luiz Carlos Pittol Martini

Universidade Federal de Santa Catarina, Florianópolis, SC, Brasil

159

luiz.martini@ufsc.br

Contribuiçáo do autor:

Único autor do trabalho- Realizou toda a pesquisa. 